\title{
Knowledge strategies aiming to improve the intellectual capital of universities
}

\author{
Ruxandra BEJINARU \\ Academy of Romanian Scientists, Bucharest, Romania \\ The University "Stefan cel Mare" of Suceava, Romania \\ ruxandrabejinaru@yahoo.com
}

\begin{abstract}
The purpose of this paper is to present a new construct of the intellectual capital structure, based on the multifield theory of knowledge and the concept of nonlinear integrators and to identify the knowledge strategies to enhance the intellectual capital of universities. The paper presents a new approach, based on metaphorical thinking and thermodynamics logic in structuring the intellectual capital, based on the multifield theory of knowledge into its basic building blocks. Considering the two levels of intellectual capital, the paper presents the main knowledge strategies to enhance the university intellectual capital. The basic building blocks of the intellectual capital are: rational, emotional, and spiritual intellectual capital. Each building block is based on the corresponding field of knowledge. There are two significant levels of intellectual capital: potential and operational. Analyzing the university intellectual capital by using this new approach is much more realistic than in the previous approaches. The new approach is based on a thermodynamics paradigm, which means we need to develop new ways of thinking, evaluating, and enhancing the intellectual capital. The paper presents an original approach, based on metaphorical thinking, by considering basic ideas from the energy realm and thermodynamics theory. Also, the paper presents a matrix of possible knowledge strategies to increase the intellectual capital of universities.
\end{abstract}

Keywords: intellectual capital, knowledge creation, knowledge sharing, strategy, universities

Please cite the article as follows: Bejinaru, R. (2017), "Knowledge strategies aiming to improve the intellectual capital of universities", Management \& Marketing. Challenges for the Knowledge Society, Vol. 12, No. 3, pp. 500-523. DOI: 10.1515/mmcks-2017-0030.

\section{Introduction}

In the knowledge economy (Hadad, 2017; Powell and Snellman, 2004; Sveiby, 1997; Viedma and Cabrita, 2012), universities become critical players as knowledge generators and regional catalysts for social and economic development. As Secundo et al. (2017, p. 610) remarked, "Knowledge produced in universities can spur business innovation, foster competitiveness and promote economic and social development", meaning a strategic move of universities from focusing exclusively on the Humboldtian missions of teaching and research (Boorner, 2008) towards a "third mission", focusing on "knowledge transfer, commercialization and innovation" (Secundo et al., 2017, p.1). Universities should align their strategies with other community actors to facilitate the technological and economic specialization on the regional level (Bejinaru, 2017; Romano et al., 2014).

The new roles of universities in the knowledge economy, the increasing pressure of academic competition due to the ranking systems, and the changes imposed by the Bologna process for the European universities (Agoston and Igret, 
2014; Curaj et al., 2012; Neave and Veiga, 2013) generated significant mutations in their governance (Chan and Lo, 2007; Christopher, 2012; Donina et al., 2015; Honada, 2013). These mutations reveal a need for a new university leadership to strengthen the correlation between the intellectual capital management and the performance management (Duderstadt, 2003; Lee, 2010; Lu, 2012). "In research centers and universities, the key issue at stake is the effective management of intangible assets and IC, which constitutes the largest proportion of universities' assets" (Secundo et al., 2015, p. 419).

The canonical model for IC evaluation is based on the tripartite structure (Andriessen, 2004; Bontis et al., 1999; Guthrie et al., 2012; MERITUM, 2002; Roos et al., 2005; Ricceri, 2008) composed of: human capital, structural capital, and relational capital. In a university, human capital refers to all the explicit and tacit knowledge, skills, and intelligence professors, researchers, managerial staff, and students have. Structural capital refers to the knowledge embedded within the structure of the organization, governance regulations, routines and procedures, and organizational culture. Relational capital reflects the knowledge flows crossing the interface between the university and its environment. Based on this tripartite model, researchers developed different systems of quantitative and qualitative indicators for measuring and reporting intellectual capital. Regardless of the number and type of indicators defined, the evaluation systems are vulnerable, due to implicit assumptions that induce the attributes of linearity and tangibility in the working concept of intellectual capital and the temptation of "accountingisation" in measuring the intellectual capital (Bratianu, 2009; Bratianu and Vasilache, 2010; Chiucchi and Dumay, 2015; Dumay, 2009; Dumay and Adams, 2014; Edvinsson, 2013; Secundo et al., 2016; Viedma, 2003; Viedma and Cabrita, 2012). For instance, Dumay and Adams (2014, p. 130) show "The use of frameworks is a valid approach to a new field of study. But it is also consistent with an industrial approach to business resources, viewing IC as a set of assets that should be identified, measured and controlled." Viedma and Cabrita (2012, p. 94) evidence the following limitations of the canonical model for the intellectual capital: the accounting view, the cause and effect relationship, the relative static approach, and the attempt to treat intangible assets as if they were tangible.

The accounting view led to what Dumay $(2009$, p. 205) called the phenomenon of accountingisation: "These contemporary IC measurement frameworks are reifying IC in the same manner in which tangible assets are portrayed within accounting, which is akin to attempting to make the intangible tangible...This practice of the "accountingisation" of IC has brought attention to the concept of IC and not its praxis, thus the ability of contemporary IC frameworks to generate "understanding" is questioned." Also, the implicit assumption of existing a direct and linear cause and effect relationship between the intellectual capital of an organization and its performance proved wrong due to the nonlinear nature of intangible resources and the process of their transformation. All these aspects show there is a gap between the intangible nature of knowledge and IC, and the evaluation systems based on tangible indicators, like those used in the Knowledge Balance Sheets of the Austrian universities (Habersam et al., 2013; Piber and Pietsch, 2006). Also, the static view of the canonical model of the intellectual capital cannot capture all the transformations of intangible resources in the process of value creation (Andriessen, 2004; Marr et al., 
2004; Nissen, 2006; Nonaka and Takeuchi, 1995; Nonaka et al., 2008; Secundo et al., 2015; Viedma and Cabrita, 2012).

These limitations became evident in evaluating and reporting the intellectual capital (Dumay, 2016; Elena and Leitner, 2013; Habersam et al., 2013; Marzo, 2014; Secundo et al., 2015). As Edvinsson (2013, p. 166) emphasises, "Too much focus on metrics and measurements means that there is not enough focus on the real strategy process, in other words, the knowledge navigating of more and more intangible dimensions or components of IC." Continuing this logic, Dumay (2016, p. 180) posits "we need to abandon reporting, and concentrate on how organisation discloses what "was previously secret or unknown", so all stakeholders understand how an organisation considers its ethical, social and environmental impacts. That leads to going beyond the rational knowledge to the emotional and spiritual knowledge (Bratianu, 2015), which has been ignored by researchers.

The purpose of this conceptual paper is to provide a new perspective on the intellectual capital structure to relax some limitations presented above. Also, we are looking to identify the generic knowledge strategies capable of increasing the intellectual capital of universities. After a discussion of the research of the intellectual capital of universities in the extant literature, a refined model of the intellectual capital is presented, and a matrix of generic knowledge strategies is analysed, as a result of searching for possible answers to the following questions:

1. How can we integrate into the intellectual capital model the transformation of the knowledge resources during the process of value creation?

2. How can we identify the adequate knowledge strategies aiming at increasing the intellectual capital of universities in a turbulent business environment?

The structure of the paper is conceived as follows. The next section presents a literature background on the intellectual capital of universities. Then, the logic of our research is presented, focusing on the metaphorical and strategic thinking. A new and refined construct of the intellectual capital is explored by using a thermodynamic lens and the energy metaphor. Having this new perspective on the intellectual capital, a matrix for generic knowledge strategies is designed. Finally, some concluding remarks and potential implications for the future theoretical and empirical research are formulated.

\section{Literature review}

The exponential development of the research field of intellectual capital (IC) generated by the big bang explosion of 1997 (Edvinsson and Malone, 1997; Stewart, 1997; Sveiby, 1997) reached the third stage, and it is on the cusp of the fourth stage (Dumay, 2013, 2016; Dumay and Garanina, 2013). In the first stage of development of IC, the focus was on defining IC and its role within organizations by contrasting its nature with the classical economic capital, based on tangible objects and financial resources (Andriessen, 2004, 2006; MERITUM, 2002; Ricceri, 2008; Roos et al., 2005). In an inspirational synthesis, Petty and Guthrie (2000, p. 156) conclude: "The aim of stage one was to render the invisible visible by creating a discourse that all could engage in. Mission accomplished."

The second stage of IC research focused on developing metrics for IC evaluation and on demonstrating IC is a driving force for increasing financial 
performances of companies (Petty and Guthrie, 2000; Dumay and Garanina, 2013). However, some empirical research projects show there is no direct correlation between increasing intellectual capital and increasing the financial performance of the firm (Dumay, 2012; Firer and Williams, 2003). The major problems in the second stage of intellectual capital research came from the fact that most researchers used the paradigm of linearity as an extension from the classical economic meaning of capital, although intellectual capital represents the intangibles of an organization, which are not linear. Linearity becomes a frontier in understanding adequately the nonlinear nature of the intellectual capital concept (Bratianu, 2009). Also, inertial thinking (Bratianu, 2007) contributed to "the continued dominance of old managerial ideals" and to "the misuse of the IC measurement frameworks" (Dumay, 2009, p. 2004). These frameworks "are reifying IC in the same manner in which tangible assets are portrayed within accounting, which is akin to attempting to make the intangible tangible. This is what the author defines as an "accountingisation" of IC" (Dumay, 2009 , p. 205). The third stage of intellectual capital research focuses on "the deeper managerial implications of managing IC in all types of organizations" (Dumay, 2009, p. 195). Both Edvinsson (2013) and Dumay (2016) consider research should go beyond IC reporting and metrics limitations. Reflecting on the captivity of IC research in the reporting thinking and of the direct correlation between IC potential and wealth creation, Dumay (2013, p. 8) advances the idea of the fourth stage of IC research, focused on "building strong economic, social and environmental eco-systems, where healthy organizations can flourish."

Against this backdrop, the research into IC in the public sector is lagging behind the research performed in business, although the public sector has a significant contribution in the GDP of most economies (Dumay et al., 2010). As emphasized by Dumay et al. (2015, p. 271), "there is an opportunity for researchers to undertake empirical research with organisations to develop and test IC frameworks and models in specific public sector contexts." The present paper attempts to capitalize on such an opportunity by providing a new perspective on IC of universities. It is a truism that universities are knowledge intensive organizations, and they have high levels of intellectual capital, although their outcomes are not measured using financial metrics. It is interesting to remark that Churches and Universities are the oldest institutions of society. Even if they changed themselves during their long history, they prove to have an impressive intellectual capital (Bratianu, 2011a, 2014; Sanchez et al., 2009; Secundo et al., 2014; Victor, 2007). In Europe, most universities are public institutions, and in concordance with all other public financed institutions, they should have full transparency concerning using their funds received from the government (Elena-Perez, 2015; Habersam et al., 2013; Leitner, 2005; Sánchez et al., 2009; Secundo et al., 2010). That requirement determined researchers to develop metrics specific for universities to evaluate and report their IC, in concordance with the goals of the second stage of IC research. The following paragraphs refer to the Spanish and Austrian experience in evaluating and reporting the intellectual capital of universities.

The Spanish experience is based on the research performed by the Autonomous University of Madrid (AUM), as a pilot university in the PRIME Network of Excellence and the Observatory European Universities (OEU). Fifteen universities 
and research institutes from eight European countries work together during two years "to develop a common framework and build a battery of indicators to measure and compare the intangible elements related to research activities" (Sánchez et al., 2007, p. 5). The ICU Report is structured into three main sections containing: 1) the vision and mission of institutions, 2) summary of intangible resources and activities, 3) a system of indicators. These indicators reflect both tangible and intangible resources, financial and non-financial outcomes, meaning to introduce descriptive or narrative elements to explain the non-financial aspects. Implementing this new model of IC reporting in the AUM led to the conclusion there were too many indicators and requirements, which made the ICU difficult to be applied and used efficiently for future decision making.

In Austria, implementing the Bologna process requirements for creating the European Higher Education Area led to new legislation for universities. For many researchers, this was an opportunity to introduce IC reporting for universities next to all other Bologna requirements in the new legislation (Elena Perez, 2007; Elena and Leitner, 2013; Habersam et al., 2013; Piber and Pietsch, 2006; Secundo et al., 2010). With the new law for universities in Austria, "Universitätsgesetz 2002" (UG), public universities in Austria have been granted greater autonomy (Habersam et al., 2013; Piber and Pietsch, 2006). That changed the spectrum of relations between universities and the Ministry of Education, Science and Culture (MESC). Although universities obtained greater autonomy, they are still held accountable for their performance and realization of their mission. "Not surprisingly, performance management techniques shape the basic elements of the new legal framework for management control and organization of universities. Together with performance previews, internal and external evaluations, contractually fixed performance agreements, the UG prescribes the annual creation of a compulsory knowledge balance sheet (KBS)" (Piber and Pietsch, 2006). Implementation of the KBS is considered by Piber and Pietsch, in the perspective of sociological new institutionalism, as an "organizational legitimation and therefore strongly influenced by rationalized myths of the social environment and mechanism of isomorphic change" (Piber and Pietsch, 2006, p. 380). From a managerial perspective, the isomorphic change refers to the implementation of strategic thinking used in business, which is a goal-oriented and top-down-related connection between "strategic objectives, operative goals, targets of employees and performance indicators" (Piber and Pietsch, 2006, p. 387). MESC "deliberately forced public universities to become more like enterprises" (Habersam et al., 2013, p. 324). The new legislation prescribes four main fields of management control, which are closely related:

- Starting with the year 2007, the universities must elaborate a strategic plan for three years and negotiate the budget associated with it and with a set of performance agreements with the MESC. Based on this strategic plan, each university signs a contract with MESC.

- The law postulates the establishment of a quality assessment system, supposed to ensure the overall performance of each university.

- Until April 30th of the second year of the 3-year-planning-period, each university must prepare a performance-preview for the third. 
- Until April 30th of every year, each university must draw up a KBS for the previous year.

It is important to note that, to elaborate the structure and the content of KBS, the Department of general management and tourism management at Innsbruck University and the Department of economic and business management at the University of Leoben decided to explore and test voluntary, such a KBS (Piber and Pietsch, 2006). The final Blueprint for the KBS has been structured into the following parts: I) Sphere of action, targets, and strategies, II) Intellectual capital, III) Key processes, IV) Output and effects of the key processes, and V) Overview and outlook. For intellectual capital, the KBS provides three well-known entities: human capital, structural capital, and relational capital. Parts I and V have a narrative format, while parts II, III, and IV are based on measurable indicators. The first KBS (2006) contained 53 indicators, most referring to tangible assets and reflecting the inertial thinking of accountingisation. Universities reacted to this rigid and arbitrary way of selecting indicators, which demonstrated a misinterpretation of the intellectual capital concept. Because of that protest coming from universities, the system of indicators have been reshaped and their number reduced to 26 in the new KBS (2010). "Some examples of abandoned indicators may illustrate this: the indicator "floor space per facility" was misleading when universities in old buildings with monument protection were compared to universities in newly built office space. The "number of books borrowed from the library was not seen as a particularly valid indicator of intellectual activity" (Habersam et al., 2013, p. 325).

In their empirical research, Habersam et al. (2013) held a series of interviews with rectors, deans, and other decision makers from two significant universities and with some key people from MESC. Most interviewers questioned the capacity of these indicators to reflect the real value of the intellectual capital of universities and the power of the KBS in managing strategically the universities in a competitive environment. They question also the intention of decision makers from MESC to create a correlation between the KBS and the budget of the universities. "The "hidden" agenda of implementing a KBS may serve to increase and tighten up control in order to distribute the (financial) resources (of the budget) more effectively. This motive is relevant for the Ministry and universities as soon as manageability and exploitability of knowledge for better performance is the common aim" (Habersam et al., 2013, p. 333). Beyond these ideas, rectors and deans understand KBS has an important role in benchmarking and ranking of the universities, and learning about the results of these competitive mechanisms, they have to adopt a strategic view in their decision making regarding the organizational knowledge dynamics. Also, there is a valuable experience in understanding the connectivity between managing intangible resources of universities, the governance process, and the dynamics of public accountability. As Habersam et al. (2013, p. 336) conclude, "The implementation of the KBS in Austria has caused direct and indirect effects. The direct effects influenced internal governance and managerial control practices, resulting in an initial change of research cultures, increasing use of benchmarking practices, and communicative activities between similar universities. However, the direct impact on managerial decisions at the university level was moderate." 
Both experiences demonstrate that many researchers do not understand the intangible nature of the intellectual capital and introduced indicators for tangible resources. Also, by using a linear logic, the result cannot reflect the value of intellectual capital, since all intangible have a nonlinear nature, and they cannot be summed up like physical objects. They should be integrated by using integration methods. Both Spanish and Austrian approaches for explaining and evaluating the intellectual capital consider too many indicators, which are not significant for measuring intellectual capital, and constitute real barriers in interpreting the results. Also, both Spanish and Austrian approaches used the canonical structure of the intellectual capital, based on human capital, structural capital, and relational capital. However, these entities are not independent, and any method of measuring them will yield erroneous results due to their interdependencies. The main difference between the Spanish and the Austrian experiences comes from the fact that, in AUM, the ICR has been considered as a pilot research, while in Austria, it has been enforced by law. For both situations, "Limitations came mostly from including both tangible and intangible resources, and using linear metrics. The solution of this problem may be to change the Newtonian paradigm of the intellectual capital model with the entropic paradigm based on rational capital, emotional capital, and spiritual capital" (Bratianu, 2014, p. 37).

Elena and Leitner (2013) and Secundo et al. (2014) go beyond the reporting stage and explore a larger perspective of a maturity model, based on experience with quality assurance maturity models used in organization assessment. The authors present a IC Maturity Model (ICMM) for universities, which is a flexible model of implementing intellectual capital approaches within European universities. The ICMM has been developed during three Mutual Learning Workshops (MLW) organized in Romania in the period October 2012 - May 2013 with international experts and practitioners. The main objectives of these MLWs are the following (Elena and Leitner, 2013, p. 136): "i) to better understanding of what IC reporting means to improve the quality of the Romanian Higher Education, ii) setting up a tailored methodology (Guidelines, Blueprints) able to help the elaboration of IC Report at the University, and iii) drafting public policy proposals for the policymakers interested in IC Management in the Knowledge Society." The ICMM is one of the main outcomes of these MLWs. The ICMM provides a theoretical continuum along which the process of IC maturity can be developed step by step. The developmental process is assessed according to the following levels of maturity: IC data collection, awareness of IC, adjustment of IC specific indicators, measurement of IC, reporting of IC, interpretation and decision making, strategy and planning. "The ICMM could be interpreted as a high level strategy rather than a new IC model, since it can be implemented also in the context of organizations already using some particular model framework. The ICMM sustains the understanding of the actual impact of IC in action when moving from the lower level to the higher level, and allows the assessment of IC value at university level to provide insights for all stakeholders involved in the decision-making process" (Secundo et al., 2015 , p. 434). Although the model enlarges the analysis perspective, it is limited in the same Newtonian logic and canonical structure of the intellectual capital, when the process converges toward measurement and reporting. 
Recently, Secundo et al. (2017) analyzed an intellectual capital framework to measure universities' third mission activities. The third mission refers to the knowledge transfer made by universities toward their communities to help their economic, social, and cultural development. The backbone of this framework is composed of human capital, organizational capital, and social capital. Organizational capital represents an extension of the structural capital and the social capital of the relational capital. These three components are interlinked by a new component reflecting their connectivity (Secundo et al., 2017, p. 3) "This connectivity among the three dimensions is introduced as a fourth dimension, to highlight that in knowledge intensive organizations, like the universities and research centers, the three IC dimensions are related each other." The research is being extended in Secundo et al. (2017) by exploring how to mobilize intellectual capital to improve European universities' competitiveness.

\section{Methodology}

The methodology used for the present conceptual research is designed in four stages: a) a critical analysis of the literature focusing on intellectual capital of universities, b) a functional analysis of the main frameworks used for evaluating and reporting intellectual capital of universities coupled with revealing the limitations of these models, c) constructing a refined structure for the intellectual capital model to relax some and to fit the specificity of academic processes, and d) identifying the most significant knowledge strategies capable of increasing the intellectual capital of universities.

We perform the critical analysis (Bryman and Bell, 2007; Moore and Parker, 2007) of the literature, focusing on intellectual capital of universities, by identifying the most significant papers published in the main stream journals and international conferences dedicated to intellectual capital and knowledge management by following insights from Dumay et al. (2015). We studied these papers and reflected upon the instruments used by researchers to analyse and measure the intellectual capital of universities. We corroborated our findings with research performed on the multidimensional Bologna process for the European universities and with recent changes in the governance of universities. The second stage is focused on the structure and functionality of the main frameworks used for evaluating and reporting the intellectual capital of universities, aiming at understanding the limitations of these frameworks and of the roots of these limitations. By the end of the second stage, we reached the conclusion that the major limitations of these frameworks come from extending the attributes of linearity and tangibility from the realm of tangible assets to the realm of knowledge fields and intellectual capital. The roots of these limitations can be found in the metaphors (Andriessen, 2006; Lakoff and Johnson, 1999) used for explaining the concept of knowledge and intellectual capital and in the inertial thinking of many researchers. A phenomenon associated to these limitations has been coined "accountingisation" by Dumay (2009). Metaphorical thinking is necessary, since "Knowledge is not a concept that has a clearly delineated structure. Whatever structure it has it gets through metaphor. Different people from different cultures use different metaphors to conceptualize knowledge" (Andriessen and Boom, 2007, p. 3). Metaphors are analogies that allow us to map one experience in terms of another 
experience, making it possible to understand complex and new situations in terms of what we know.

In the third stage, we explored a new perspective of expressing the intellectual capital components in correlation with the multifield theory of organizational knowledge (Bratianu, 2015). That means to go beyond the human capital, structural capital, and relational capital and look for some basic components that don't overlap anymore. Also, by using the metaphorical thinking and energy as a source domain, we postulated the possibility of having a continuum of intellectual capital defined by its potential and operational levels. The first level is akin to the potential energy and the second level to the kinetic energy. This new perspective comes from thermodynamics and complexity theory (Stacey, 2001), and it reveals the dynamic property of the intellectual capital. In the last stage of our research, we integrated strategic thinking (Nonaka and Zhu, 2012; Ricceri, 2008) with knowledge management (Nonaka and Takeuchi, 1995; Zack, 1999) and produced a matrix containing generic knowledge strategies to increase the intellectual capital of universities.

\section{The new paradigm for understanding intellectual capital of universities}

The paradigm of conceiving intellectual capital composed of human capital, structural capital, and relational capital is based on interdependent entities and Newtonian logic or linear thinking (Bratianu, 2007, 2009). However, a university is a knowledgeintensive organization with processes that differ from those in industrial organizations. Teaching, learning, knowledge generation through research, and knowledge transfer toward community are complex and nonlinear processes that cannot be evaluated and reported accurately by frameworks based on linear logic. There is a need for a new paradigm of understanding and measuring knowledge processing and intellectual capital dynamics.

The new paradigm is based on the multifield theory of knowledge (Bratianu, 2015) and organizational nonlinear integrators. The multifield theory of knowledge is based on three main ideas: a) knowledge is conceived as a field, which is an intangible entity; b) there are three fundamental knowledge fields: rational, emotional, and spiritual; and c) knowledge dynamics means transformation of one form of knowledge into another form. Knowledge explanation departs from the stock-and-flow metaphor (Bolisani and Oltramari, 2012; Nonaka et al., 2008) and the fluid flow dynamics, which represents a Newtonian motion. The multifield theory is based on the knowledge metaphor as energy (Bratianu and Andriessen, 2008) and thermodynamic transformations (Atkins, 2010). The fact that energy is a field and there are several forms of energy (i.e., mechanical, thermal, electrical, nuclear etc.) can be mapped from the source domain into the target domain (Andriessen, 2006; Lakoff and Johnson, 1999), to postulate that knowledge can be conceived as a field, and we may postulate several forms of knowledge: rational, emotional, and spiritual. Rational knowledge results from processing data and information using our rationality. Rational knowledge has been the only knowledge accepted by philosophers and scientists due to its objectivity (Nonaka and Takeuchi, 1995; Polanyi, 1983). Education in schools and universities is based on rational knowledge, and that explains why intellectual capital is framed in terms of rational knowledge. Emotional knowledge results from 
body interaction with the environment and processing sensory system's information by using emotional intelligence (Damasio, 2012; Goleman, 1995; Kahneman, 2011). Emotional knowledge plays an important role in making decisions (Hill, 2008; Kotter, 1996). Spiritual knowledge reflects our search for understanding deeper meanings of our existence and the value system we use in making decisions (Giacalone and Jurkiewicz, 2010; Zohar and Marshall, 2000). Spiritual knowledge is fundamental in understanding corporate social responsibility phenomena (Basu and Palazzo, 2008).

Bratianu (2011b) demonstrates each component of the canonical model of intellectual capital (i.e., human capital, structural capital, and relational capital) contains rational knowledge, emotional knowledge, and spiritual knowledge, which leads to the conclusion these three entities are not independent, although all the metrics used so far to measure and report intellectual capital are based on this hypothesis. Human capital, structural capital, and relationship capital cannot be the basic blocks of intellectual capital; they result from combinations of other basic building blocks, which we have to identify and define. Since knowledge represents the main content of the intellectual capital, we can assume the basic building blocks of the organizational intellectual capital are the following: rational intellectual capital, emotional intellectual capital, and spiritual intellectual capital. Human capital, structural capital, and relational capital may remain in the final structure but only as meta-components. Figure 1 illustrates the new composition of the organizational intellectual capital. The new components - rational IC, emotional IC, and spiritual IC are independent entities, and any measurement of them will eliminate the overlapping zones.

Instead of counting the number of computers in a university or the square meters of the educational areas, it makes much more sense to evaluate the rational IC, emotional IC, and spiritual IC. If for rational IC things are clear, since we equated knowledge with rational knowledge, which constitutes the main content of rational IC, for emotional IC, we have to conceive new metrics starting with the experience obtained from metrics designed to measure emotional intelligence. Similar ideas may be used for measuring spiritual IC, since there are methods for evaluating cultures and organizational cultures. It is much more adequate to evaluate the rewarding system of a university, which is part of the emotional IC, than to count the number of computers, classrooms, and their surface in square meters for understanding the value of intellectual capital of a university. In the same direction, we may evaluate the vision and the value system of a university to understand its spiritual intellectual capital. A university is a community of professors, non-teaching staff, and students, who share the same values and aspirations and have the same vision about the role of the university in society. For instance, the mission statement of the Graduate School of Business, Stanford University, USA, gives the image of its rational, emotional, and spiritual capital in a beautiful and synthetic way: "Our mission is to create ideas that deepen and advance our understanding of management and with those ideas to develop innovative, principled, and insightful leaders who change the world" (http://www.gsb.stanford.edu). The level of this spirituality correlates positively with the contribution of each member to the performance of the university. The worldclass universities have high levels of spirituality and emotional identity from their members. These new aspects cannot be seen and measured in the old paradigm of the 
canonical model of intellectual capital, no matter how many indicators we may consider in the evaluation system. Figure 1 presents the new structure of the university intellectual capital, where the basic building blocks are rational IC, emotional IC, and spiritual IC. These components are comparable with those proposed by Massingham and Tam (2015) for human capital: employee capability, employee satisfaction, and employee commitment. In their new conceptualization of human capital, Massingham and Tam (2015, p. 394) combine conventional views with "the individual's emotional relationship with their organization. Psychological contract is the emotional relationship between the individual and employer and measures organizational commitment." Employee capability can be reflected by the rational intellectual capital; employee satisfaction is contained in the emotional intellectual capital, and employee commitment suggests the spiritual intellectual capital. These ideas are emphasized from a different perspective by Dumay (2009, p. 199): "Finally, examining human capital components in Table III indicates the importance of attracting, engaging and retaining employees."

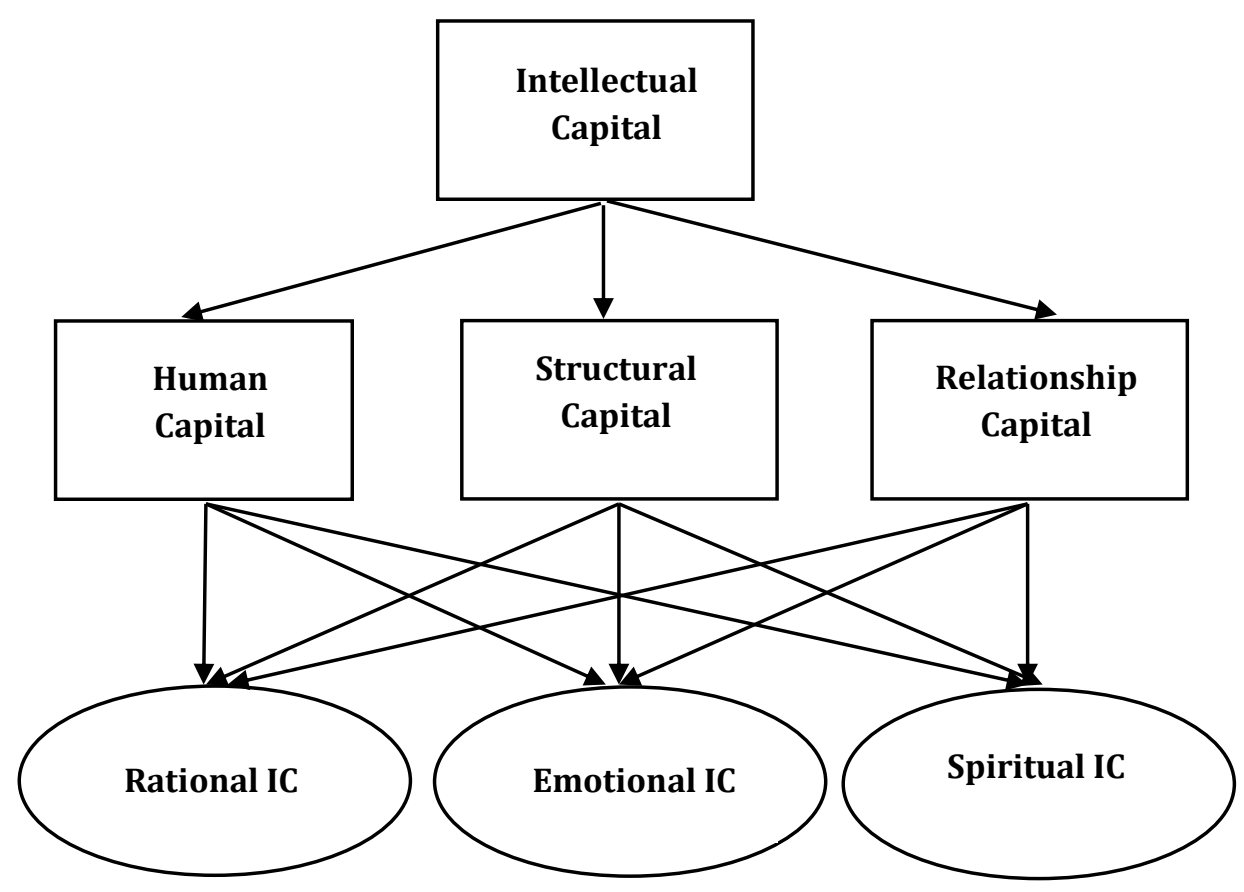

Figure 1. The new structure of the organizational intellectual capital

Source: Adaptation after Bratianu (2011b).

Almost all authors discussing intellectual capital refer to its potential value. As defined by Roos et al. (2005, p. 19), intellectual capital represents "all nonmonetary and nonphysical resources" of an organization. Then, it is underlined that "These IC resources all form the basis for potential competitive advantage" (Roos et al., 2005, p.19). More clearly, Andriessen (2004, p. 68) states: "Capital is a stock. Treating intellectual capital as a stock offers interesting perspectives on the potential of firms." Then, extending the metaphor from "stock" to "stock-and-flow", Andriessen (2004, p. 68) remarks: "The concept of intellectual capital stocks and flows creates an interesting new perspective on organizations. We can describe organizations as a

Vol. 12, No. 3, Autumn, pp. 90-103, ISSN 1842-0206 | Management \& Marketing. Challenges for the Knowledge Society 
dynamic system of financial, tangible, and intangible stocks and flows." In the new dynamic framework of intellectual capital, we can define two distinct levels of manifestation of the intellectual capital by using the metaphor of potential and kinetic energy: the potential intellectual capital as a mapping result from the potential energy and the operational intellectual capital as a mapping result of the kinetic energy. The potential intellectual capital is transforming continuously into operational intellectual capital because of the work of nonlinear integrators. Here, we introduce the concept of "integrator", which can be conceived as a powerful field of forces capable of combining two or more elements into a new entity, based on interdependence and synergy. These elements may have a physical or virtual nature, and they must possess the capacity of interacting in a controlled way. The nonlinear integrators include: management, leadership, and organizational culture. Technology and processes can be linear or nonlinear as a result of the complexity built in each. Management is centered on rational intellectual capital, since most of its principles come from economics. Leadership integrates emotional and spiritual intellectual capital in a balanced manner rational, but it works mostly by using emotional knowledge to influence people. Organizational culture is centered on spiritual capital and contributes to the development of a certain working spirituality. The potential intellectual capital shows the upper limit of which an organization might perform in an idealistic business environment. However, in real life, only a part of this potential is transformed by integrators into operational intellectual capital, responsible for economic performance of the organization (Bratianu and Orzea, 2013). This idea of considering two levels of intellectual capital and a continuous process of transformation of the potential intellectual capital into the operational one opens new perspectives for research and for understanding the real phenomena within any organization. As underlined by Secundo et al. (2016, p. 1907), "Some features are considered relevant when analyzing and defining an integrated IC management model: the potential value of IC, its dynamic and the organization specific nature." From a practical point of view, a university may have excellent professors and tangible resources, but if there is a mediocre management and low stimulating organizational culture, the university performances are low. That means the new structure of the intellectual capital can explain university performance better than the static structure composed of human capital, structural capital, and relationship capital. An illustration of the new framework for intellectual capital is presented in figure 2 .

The concept of nonlinear integrators can be an answer to the need of incorporating the idea of dynamics into the intellectual capital model, but not in the Newtonian sense of motion (Kianto, 2007; Nissen, 2006), resulting from the knowledge as stocks-and-flows metaphor. Changing the paradigm of Newtonian logic with that of thermodynamics logic, intellectual capital is understood as a transformation in time. In this way, we introduce the longitude dimension suggested by Edvinsson (2013, p. 166): "The traditional unit of longitude measurement is time. Thus, IC can be seen as three dimensional, in which the third dimension is the longitude strategy formulating process. It is made when considered in combination with altitude and latitude." The longitudinal dimension is also advocated by Chiucchi and Dumay (2015), and Dumay et al. (2015), since intellectual capital should not be considered like a picture at a moment, but more like a journey. By introducing the idea 
of the nonlinear integrators, we answer the need of connectivity and interactions between the components of the intellectual capital (Dumay 2016; Secundo et al., 2017; Skoog, 2003).

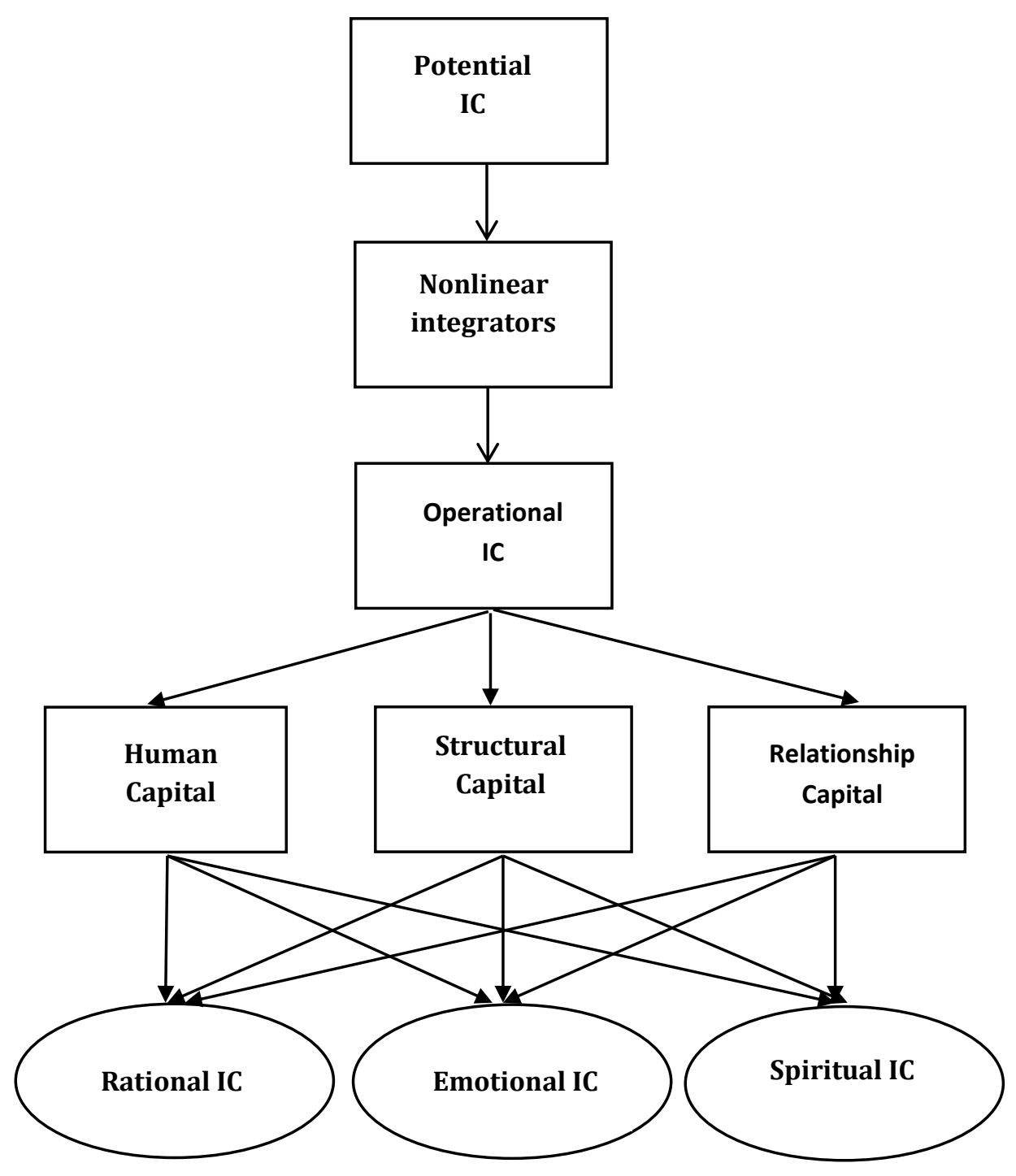

Figure 2. The framework of intellectual capital based on the new paradigm

Source: Adaptation after Bratianu (2011b).

In his inspirational paper, Dumay (2009, p. 194) suggests introducing ideas from the complexity theory into the intellectual capital research to explain the nonlinear interactions between the constituent parts of the intellectual capital: "Complexity theory deals with understanding systems where there is a nonlinear relationship in the interactions between the elements of a system. These systems are characterized by the fact that small changes to one or two parameters may have significant, emerging and unexpected effect(s) on the entire system." 


\section{Knowledge strategies for enhancing intellectual capital in universities}

Edvinsson $(2013,166)$ emphasizes the need to change the focus from metrics and measuring intellectual capital to strategy of developing and using it efficiently: "Too much focus on metrics and measurement means that there is not enough focus on the real strategy process, in other words, the knowledge navigating of more and more intangible dimensions or components of IC." With the new framework in mind, we can think of knowledge strategies to increase the potential intellectual capital and the operational intellectual capital of universities. We focus only on the knowledge strategies due to their emergence in the last two decades (Bolisani and Oltramari, 2012; Bolisani et al., 2013; Denford and Chan, 2011; De Toni et al., 2011; Donate and Canales, 2012; Ichijo, 2007; Kim et al., 2003; Kim et al., 2014; Sveiby, 2001; Zack, 1999), and to the fact that strategies for increasing integrators' efficiency can be found in dedicated works. According to Zack (1999, p. 131), knowledge strategy "can be thought of as balancing knowledge-based resources and capabilities to the knowledge required for providing products or services in ways superior to those of competitors. Identifying which knowledge-based resources and capabilities are valuable, unique, and inimitable as well as how those resources and capabilities support the firm's product and market positions are essential elements of a knowledge strategy." Knowledge strategies are created at the interface between the internal field of forces and external field of forces for each organization. They result from integrating strategic thinking and knowledge management and have a direct impact on intellectual capital. In this perspective, knowledge is a strategic resource (Bolisani and Bratianu, 2017; Davenport and Prusak, 2000; Nonaka and Takeuchi, 1995). In figure 3, we present the main knowledge strategies to increase the university potential and operational intellectual capital.

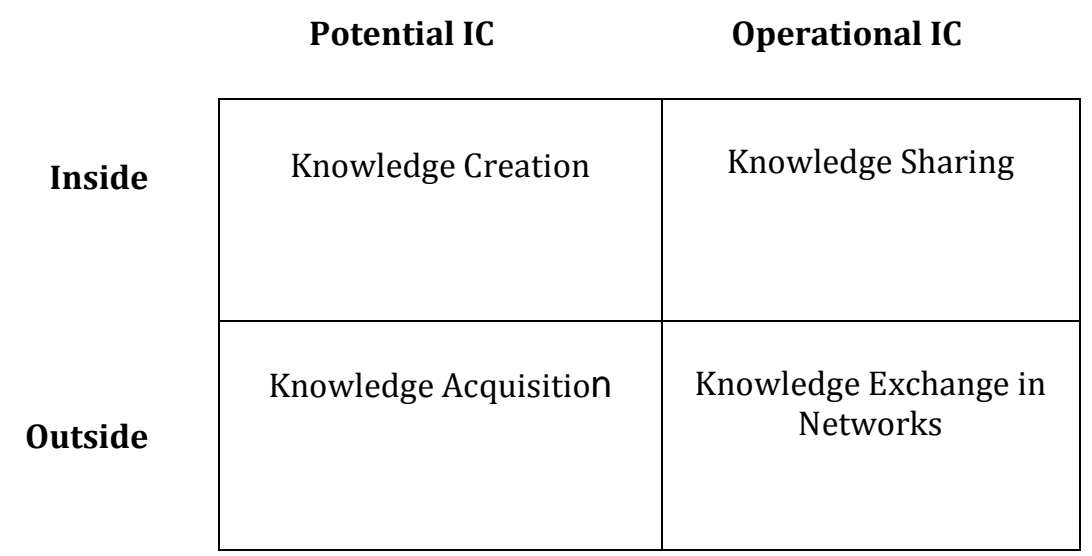

Figure 3. The main knowledge strategies to increase the university IC

Source: Adaptation after Bratianu and Bejinaru (2017).

Knowledge creation is the most powerful strategy for increasing the university strategy, especially for research universities, to stimulate research and knowledge exploration through a well-defined rewarding system, which should be conceived to impact all components of the intellectual capital (i.e., rational, emotional, and spiritual). If rational knowledge is directly related to fundamental research in science, 
emotional knowledge is related to the organizational culture and creating a climate of trust and cooperation. Emotional knowledge and spiritual knowledge contribute to culture that encourages research efforts and stimulates new ideas in science, technology, and business. Unfortunately, in many universities, the organizational culture is based on the idea that performing research is compulsory. However, theoretical studies and experimental research demonstrated that knowledge creation is strongly related to the emotional and spiritual intelligences, a fact that makes necessary a complex rewording system for all contributors from professors to students. All the world class universities are known for their impressive research programs and results published in the mainstream international journals. "There is an ample evidence that universities, especially research universities are both intellectual and economic development engines" (Victor, 2007, p. 55). Knowledge creation strategy is fundamental for increasing the potential intellectual capital of the university and for achieving a competitive advantage on the global market of higher education. At the same time, knowledge creation allows universities to accomplish their third mission by transferring new knowledge toward their communities (Secundo et al., 2017).

Knowledge creation is an integrated process, starting from individuals and ending in a group or organization, as a result of a series of transformations, described by Nonaka (1994) in the famous SECI (i.e. Socialization, Externalization, Combination, and Internalization) model: "Although ideas are formed in the minds of individuals, interaction between individuals typically plays a critical role in developing these ideas." The strategy of knowledge creation should be correlated with that of stimulating organizational learning (Argote, 2013; Senge, 1999) and its financial and technological infrastructure. At the same time, we should not forget that most research grants are obtained through competitions, which means for the university to develop those dynamic capabilities (Teece, 2009) necessary to win in research competitions.

Knowledge sharing used in different ways constitute the best method for increasing the operational intellectual capital as a result of the increase of the average level of knowledge in the university. That means, for the same value of the potential intellectual capital, the level of operational capital can be increased by implementing the strategy of knowledge sharing (Nesheim and Gressgard, 2014; 0'Dell and Hubert, 2011). Since universities have age layers of faculty staff and researchers, this strategy can be extended to intergenerational learning (Lefter et al., 2011). However, knowledge sharing needs a culture of trust and cooperation (Nonaka and Takeuchi, 1995) to stimulate the willingness of people to share their experience. The strategy of knowledge sharing should start with identifying the specific barriers within the university and then to conceive solutions for overcoming them. The practical solution is to create communities of practice (Wenger et al., 2002), based on common professional interests and expectations. Also, an increasing role in knowledge sharing is playing now by social media networks and applications.

Knowledge acquisition is a strategy intended to bring in new knowledge and experience from the surrounding environment. This strategy is in concordance with the known-unknowns position within the known-unknown knowledge matrix (Dalkir, 2012). Knowledge acquisition may embrace the form of hiring best experts in the field 
to follow an academic career within the university, acquiring mostly tacit knowledge and talent, which are rare ingredients for university performance. Once the university potential increases because of that acquisition, it is important to have nonlinear integrators to transform the potential into a higher level of operational intellectual capital (Bratianu, 2011a). Knowledge acquisition becomes an important strategy for increasing the intellectual capital of universities with the exponential development of Big Data (Secundo et al., 2016).

Knowledge exchange in a university network. Universities throughout the world search for opportunities to create networks, based on shared values and academic interests. These networks develop rules and strategies about exchanging students, professors, and knowledge in implicit and explicit ways. Considering the increased competition among universities on the global market of higher education services and research and the benefits of the network effect, "it is imperative that researchers from different universities to share information and knowledge, and learn from the more developed systems and from the high-performance education institutions" (Vătămănescu et al., 2016, p. 62). Existing research suggests networking of people and organizations becomes an important strategy for knowledge exchange and stimulating innovation (Kodama, 2011). An excellent example could be the Mutual Learning Workshops (MLWs), "organized as a mean to bring together international experts and practitioners to share their views and experience on IC reporting and setting up task forces" (Secundo et al., 2015, p. 428).

\section{Conclusions and ways forward}

Universities are under increasing pressure to change their governance models and their management such that they can comply with a third mission and the new changes in the business environment. The isomorphic change phenomenon leads to changing their focus from a collegial academic management to a corporative management, based on strategic thinking and competitiveness. Against this backdrop, contemporary research into higher education converges toward the value of the intellectual capital of universities and the need to go beyond the conventional models of measuring and reporting it. Aligned to these needs, the present paper analyzes the spectrum of research focused on intellectual capital of universities and tries to evidence the main limitations of operational models and their roots. One of the most common limitations comes from inertial thinking in transferring the linearity property from the realm of tangible assets into the realm of intellectual capital, based on intangible resources and nonlinear processes. The tripartite structure of the canonical model of the intellectual capital is based on entities (i.e., human capital, structural capital, and relational capital), which are overlapping from knowledge point of view, since they represent meta-structures in the architecture of organizational knowledge dynamics and not basic building blocks. That phenomenon becomes evident, especially when examining the systems of indicators used by different researchers or imposed by legislation, like with the Austrian universities, in measuring and reporting intellectual capital.

The purpose of this paper is twofold. First, it proposes a new perspective at looking at the structure of the intellectual capital by considering the energy metaphor and the need to integrate the dynamics of intellectual capital into the new model along 
its longitude dimension. Second, the paper is trying to find practical ways of identifying knowledge strategies capable of increasing the intellectual capital of universities. To fulfill the first objective, we use the metaphorical thinking and change the stocks-and-flows metaphor of knowledge with the energy metaphor. That allows us to interpret knowledge as a field without tangible attributes and to postulate several forms of knowledge, the same way in which we deal with mechanical energy, thermal energy, and electrical energy and with their reciprocal transformations. Using the multifield theory of knowledge, we consider three basic knowledge fields: rational, emotional, and spiritual. Since knowledge constitutes strategic resources for a university, we postulate these fields of knowledge should define the components of the intellectual capital, a new refined structure of intellectual capital having as basic building blocks: rational intellectual capital, emotional intellectual capital, and spiritual intellectual capital. Each form of intellectual capital can transform one into each other, satisfying the connectivity need. Human capital, structural capital, and relational capital can remain in the model but as meta-entities at a higher level of complexity.

Capturing suggestions from the literature review, concerning the time line of intellectual capital and its interpretation as a journey along its longitude, and trying to incorporate into the model the idea of intellectual capital dynamics, we use the analogy of energy transformation and suggest two distinct levels of intellectual capital: potential level and operational level. In the same way in which potential energy is transformed into kinetic energy and generates power, we may consider the transformation of the potential intellectual capital into operational intellectual capital and generate action. The transformation is performed by powerful fields able to mobilize organizational resources we call nonlinear integrators as a consequence of their nonlinear propriety. In this way, performance is not related directly to the potential level of intellectual capital but to the operational level, which means intellectual capital in action. As nonlinear integrators we consider: management, leadership, and organizational culture. Although some of these ideas are found in the empirical research performed, it is the first time to integrate them into a coherent model for intellectual capital. This model explains why many universities, which are comparable from resources point of view, have different performances. In conclusion, the suggested model for the intellectual capital integrates strategic resources and their transformations in time because of the nonlinear integrators contribution.

Analyzing the knowledge strategies that can increase the intellectual capital of a university leads to a matrix determined by the potential and operational intellectual capital states and the internal and external university environment. For increasing the potential intellectual capital, the matrix presents knowledge creation and knowledge acquisition as the main knowledge strategies. For increasing the operational intellectual capital, the matrix presents knowledge sharing and knowledge exchange in networks as main knowledge strategies. The operational level of intellectual capital depends on the efficiency work performed by the nonlinear integrators, but that is a different research topic. For world-class universities, knowledge creation is the most powerful strategy. These generic knowledge strategies may answer to the second research question we formulated initially. 
The present paper has implications from both theoretical and practical viewpoints. Since the suggested model for the intellectual capital is based on the metaphorical thinking and the analogy with the energy field, it can be further detailed and adjusted to fit specific contexts. The practical implications come from the fact that the focus in the research into intellectual capital of university will not be on evaluating tangible and intangible resources but of their full dynamics and their transformation in final products and services. Future research is necessary to get insight into each knowledge strategy to reveal the possible impact on the intellectual capital and then to conceive ways of implementing them in real life universities in concordance with their vision and mission. In the knowledge economy and turbulent times, universities must adapt and find the most adequate strategies to enhance their knowledge and intellectual capital wealth to create value for society and to contribute significantly to the development of their communities.

\section{Limitations}

The main limitation of the present paper comes from it being a conceptual paper. The model suggested for the intellectual capital is based on metaphorical thinking and the analogy with the energy field, changing the Newtonian paradigm with that offered by thermodynamics. This model must be tested in future research to find its strong and weak aspects. Also, the matrix we presented shows only four main generic knowledge strategies, but in practice, researchers could expand them in concordance with the context specificity.

Acknowledgement: We would like to acknowledge the financial support received for this research from the Academy of Romanian Scientists, Romania, within the Research Program No. 11/2017: "Developing strategies to implement knowledge economy in Romania".

\section{References}

Agoston, S. and Igret, R.S. (2014), "Implementation of Bologna reforms: a comparative analysis between participating countries", in Dima, A.M. (Ed.), Handbook of research on trends in European higher education convergence, IGI Global, Hershey, pp. 106-123.

Andriessen, D. (2004), Making sense of the intellectual capital: designing a method for valuatin of intengibles, Elsevier, Amsterdam.

Andriessen, D. (2006), "On the metaphorical nature of intellectual capital: a textual analysis", Journal of Intellectual Capital, Vol. 7, No. 1, pp. 93-100.

Andriessen, D. and Boom, M.d. (2007), "Asian and western intellectual capital in encounter", Paper presented at IC-Congress 2007, Inholland University of Applied Sciences, Haarlem, The Netherlands.

Argote, L. (2013), Organizational learning: creating, retaining and transferring knowledge, $2^{\text {nd }}$ edition, Springer, New York.

Atkins, P. (2010), The laws of thermodynamics: a very short introduction, Oxford University Press, Oxford.

Basu, K. and Palazzo, G. (2008), "Corporate social responsibility: a process model of sensemaking", Academy of Management Review, Vol. 33, No. 1, pp. 122-136. 
Bejinaru, R. (2017), "Universities in the knowledge economy", Management Dynamics in the Knowledge Economy, Vol. 5, No. 2, pp. 251-271.

Bolisani, E. and Bratianu, C. (2017), "Knowledge strategy planning: an integrated approach to manage uncertainty, turbulence, and dynamics", Journal of Knowledge Management, Vol. 21, No. 2, pp. 233-253.

Bolisani, E. and Oltramari, A. (2012), "Knowledge as a measurable object in business contexts: a stock-and-flow approach", Knowledge Management Research \& Practice, Vol. 10, No. 3, pp. 235-286.

Bolisani, E., Paiola, M. and Scarso, E. (2013), "Knowledge protection in knowledgeintensive services", Journal of Intellectual Capital, Vol. 14, No. 2, pp. 192-211.

Bontis, N., Dragonetti, N.C., Jacobsen, K. and Roos, G. (1999), “The knowledge toolbox: a review of the tools available to measure and manage intangible resources", European Management Journal, Vol.17, No.4, pp.391-402.

Bourner, T. (2008), "The fully functioning university", Higher Education Review, Vol. 40 , No. 2, pp. 2-23.

Bratianu, C. (2007), "Thinking patterns and knowledge dynamics”, In Martis, B. and Remenyi, D. (Eds.). Proceedings of the $8^{\text {th }}$ European Conference on Knowledge Management, Consorci Escola Industrial de Barcelona, Spain, 6-7 September 2007, Academic Conferences Limited, Reading, pp. 152-156.

Bratianu, C. (2009), "The frontier of linearity in the intellectual capital metaphor", In Stam, C. and Andriessen, D. (Eds.), Proceedings of the European Conference on Intellectual Capital, Inholland University of Applied Sciences, Haarlem, The Netherlands, 28-29 April 2009, Academic Publishing Limited, Reading, pp.97103.

Bratianu, C. (2011a), "Universities as knowledge-intensive learning organizations", In Eardley, A. and Uden, L. (Eds.), Innovative knowledge management: concepts for organizational creativity and collaborative design, IGI Global, Hershey, pp. 1-17.

Bratianu, C. (2011b), "A new perspective of the intellectual capital dynamics in organizations". In Vallejo-Alonso, B., Rodriguez-Castellanos, A. and Arregui Ayastuy, G. (Eds.). Identifying, measuring, and valuing knowledge-based intangible assets: new perspectives, IGI Global, Hershey, pp. 1-21.

Bratianu, C. (2014), "Intellectual capital of the European universities". In Dima, A.M. (Ed.). Handbook of research on trends in European higher education convergence, IGI Global, Hershey, pp. 24-43.

Bratianu, C. (2015), Organizational knowledge dynamics: managing knowledge creation, acquisition, sharing, and transformation, IGI Global, Hershey.

Bratianu, C. and Andriessen, D. (2008), "Knowledge as energy: a metaphorical analysis". In Harorimana, D. and Watkins, D. (Eds.), Proceedings of the $9^{\text {th }}$ European Conference on Knowledge Management, Southampton Solent University, UK, 4-5 September 2008, Academic Publishing, Reading, pp.75-82.

Bratianu, C. and Bejinaru, R. (2017), "Knowledge strategies for increasing IC of Universities". In Lopez, I.T. and Serrasqueiro, R. (Eds.), Proceedings of the $9^{\text {th }}$ European Conference on Intellectual Capital, Instituto Universitaria de Lisboa, Portugal, 6-7 April 2017, pp. 34-42, Academic Conferences and Publishing International, Reading. 
Bratianu, C. and Orzea, I. (2013), “The entropic intellectual capital model”, Knowledge Management Research \& Practice, Vol. 11, No. 2, pp. 133-141.

Bratianu, C. and Vasilache, S. (2010), "A factorial analysis of the managerial linear thinking model", International Journal of the Innovation and Learning, Vol. 8, No. 4, pp. 393-407.

Bryman, A. and Bell, E. (2007), Business research methods, Second edition, Oxford University Press, Oxford.

Chan, D. and Lo, W. (2007), "Running universities as entreprises: university governance changes in Hong Kong", Asia Pacific Journal of Education, Vol. 27, No. 3, pp. 305-322.

Chiucchi, M.S. and Dumay, J. (2015), “Unlocking IC”, Journal of Intellectual Capital, Vol. 16, No. 2, pp. 305-330.

Christopher, J. (2012), “Governance paradigms of public universities: an international comparative study", Tertiary Education and Management, Vol. 18, No. 4, pp. 335-351.

Curaj, A., Scott, P., Vlasceanu, L. and Wilson, L. (2012), European higher education at the crossroads: between the Bologna process and national reforms, Springer, Heidelberg.

Dalkir, K. (2012), Knowledge management in the theory and practice, $2^{\text {nd }}$ Edition, MIT Press, Boston.

Davenport, T.H. and Prusak, L. (2000), Working knowledge: how organizations manage what they know, Harvard Business School Press, Boston.

Damasio, A.R. (2012), Self comes to mind: constructing the conscious brain, Vintage Books, New York.

Denford, J.S. and Chan, Y.E. (2011), "Knowledge strategy typologies: defining dimensions and relationships", Knowledge Management Research \& Practice, Vol. 9, No. 2, pp. 102-119.

De Toni, A.F., Nonino, F. and Pivetta, M. (2011), “A model for assessing the coherence of companies' knowledge strategy", Knowledge Management Research \& Practice, Vol. 9, pp. 327-341.

Donate, M.J. and Canales J.I. (2012), "A new approach to the concept of knowledge strategy", Journal of Knowledge Management, Vol. 16, No. 1, pp. 22-44.

Donina, D., Meoli, M. and Paleari, S. (2015), "The new institutional governance of Italian state universities: what role for the new governing boards?", Tertiary Education and Management, Vol. 21, No. 1, pp. 16-28.

Duderstadt, J.J. (2003), A university for the 21st century, The University of Michigan Press, Ann Arbor.

Dumay, J. (2009), "Intellectual capital measurement: a critical approach", Journal of Intellectual Capital, Vol. 10, No. 2, pp. 190-210.

Dumay, J. (2012), "Grand theories as barriers to using IC concepts", Journal of Intellectual Capital, Vol.13, No.1, pp.4-15.

Dumay, J. (2013), "The third stage of IC: towards a new IC future and beyond", Journal of Intellectual Capital, Vol. 14, No. 1, pp. 5-9.

Dumay, J. (2016), “A critical reflection on the future of intellectual capital: from reporting to disclosure”, Journal of Intellectual Capital, Vol. 17, No. 1, pp. 168184. 
Dumay, J. and Adams, M. (2014), “The learning journey of IC missionaries: intuition, control and value", Electronic Journal of Knowledge Management, Vol. 12, No. 2, pp. 128-136.

Dumay, J., Bernardy, C., Guthrie, J. and Demartini, P. (2016), “Integrated reporting: a structural literature review, Accounting Forum, Vol. 40, No. 3, pp. 166-185.

Dumay, J. and Garanina, T. (2013), "Intellectual capital research: a critical examination of the third stage", Journal of Intellectual Capital, Vol. 14, No. 1, pp. 10-25.

Dumay, J., Guthrie, J. and Puntillo, P. (2015), "IC and public sector: a structured literature review", Journal of Intellectual Capital, Vol. 16, No. 2, pp. 267-284.

Edvinsson, L. and Malone, M. (1997), “Intellectual capital: realizing your company's true value by finding its hidden brainpower", Harper Business, New York.

Edvinsson, L. (2013), "IC 21: reflections from 21 years of IC practice and theory", Journal of Intellectual Capital, Vol. 14, No. 1, pp. 163-172.

Elena Perez, S. (2007), Governing the university of the 21 $1^{\text {st }}$ century: intellectual capital as a tool for strategic management. Lessons from the European experience, Ph.D. Thesis, Universidad Autonoma de Madrid, Spain, July 2007.

Elena Perez, S. and Leitner, K.H. (2013), "Coupling with standardization and diversity: intellectual capital reporting guidelines for European universities”, Proceedings of the $5^{\text {th }}$ European Conference on Intellectual Capital, University of the Basque County, Bilbao, Spain, 11-12 April 2013, pp. 132-141.

Elena Perez, S., Leitner, K.H., Secundo, G. and Martinaitis, Z. (2015), "Shaping new managerial models for European universities: the impact of reporting and managing IC. In Ordonez de Pablos, P. (Ed.), Intellectual capital in organizations: nonfinancial reports and accounts, Routledge, London, pp. 150166.

Firer, S. and Williams, S.M. (2003), "Intellectual capital and traditional measures of corporate performance”, Journal of Intellectual Capital, Vol. 4, No. 3, pp.348360.

Giacalone, R.A. and Jurkiewicz, C.L. (2010), Hanbook of workplace spirituality and organizational performance, M.E. Sharpe, New York.

Goleman, D. (1995), Emotional intelligence, Bantam, New York.

Guthrie, J., Ricceri, F. and Dumay, J. (2012), "Reflections and projections: a decade of intellectual capital accounting research", The British Accounting Review, Vol. 44, pp. 68-82.

Habersam, M., Piber, M. and Skoog, M. (2013), "Knowledge balance sheets in Austrian universities: the implementation, use and re-shaping of measurement and management practices", Critical Perspectives on Accounting, Vol. 24, pp. 319337.

Hadad, S. (2017), "Knowledge economy: Characteristics and dimensions", Management Dynamics in the Knowledge Economy, Vol. 5, No. 2, pp. 203-225.

Hanada, S. (2013), “Japan's higher education incorporation policy: a comparative analysis of three stages of national university governance", Journal of Higher Education Policy and Management, Vol. 35, No. 5, pp. 537-552.

Hill, D. (2008), Emotionomics: leveraging emotions for business success, Kogan Page, London. 
Ichijo, K. (2007), "The strategic management of knowledge". In Ichijo, K. and Nonaka, I. (Eds.), Knowledge creation and management: new challenges for managers, Oxford University Press, Oxford, pp. 121-145.

Kahneman, D. (2011), Thinking, fast and slow, Farrar, Straus and Giroux, New York.

Kianto, A. (2007), "What do we really mean by the dynamic dimension of intellectual capital?', International Journal of Learning and Intellectual Capital, Vol. 4, No. 4, pp. 342-356.

Kim, Y.G., Yu, S.H. and Lee, J.H. (2003), "Knowledge strategy planning: methodology and case", Expert Systems with Applications, Vol. 24, No. 3, pp. 295-307.

Kim, T.H., Lee, I.N., Chun, J.U. and Benbasat, I. (2014), "Understanding the effect of knowledge management strategies on knowledge management performance: a contingency perspective", Information \& Management, Vol. 51, pp.398-416.

Kodama, M. (2011), Knowledge integration dynamics developing strategic innovation capabilities, World Scientific, Singapore.

Kotter, J. (1996), Leading change, Harvard Business School Press, Boston.

Lakoff, G. and Johnson, M. (1999), Philosophy in the flesh: the embodied mind and its challenge to the western thought, Basic Books, New York.

Lee, S.H. (2010), "Using fuzzy AHP to develop intellectual capital evaluation model for assessing their performance contribution in a university", Expert Systems with Applications, Vol. 37, pp. 4941-4947.

Lefter, V., Bratianu, C., Agapie, A., Agoston, S. and Orzea, I. (2011), "Intergenerational knowledge transfer in the academic environment of knowledge-based economy", Amfiteatru Economic, Vol. 13, No. 30, pp. 392-403.

Lu, W.M. (2012), "Intellectual capital and university performance in Taiwan", Economic Modelling, Vol. 29, pp. 1081-1089.

Marr, B., Schiuma, G. and Neely, A. (2004), "The dynamics of value creation: mapping your intellectual capital performance drivers", Journal of Intellectual Capital, Vol. 5 No. 2, pp. 312-325.

Marzo, G. (2014), "Improving internal consistency in IC research and practice: IC and the theory of the firm", Journal of Intellectual Capital, Vol. 15, No. 1, pp. 38-64.

Massingham, P.R. and Tam, L. (2015), "The relationship between human capital, value creation and employee reward", Journal of Intellectual Capital, Vol. 16, No. 2, pp. 390-418.

MERITUM (2002), Guidelines for managing and reporting of intangibles, Fundacion Airtel Movil, Madrid.

Moore, B.N. and Parker, R. (2007), Critical thinking, $8^{\text {th }}$ edition, McGraw Hill, New York.

Neave, G. and Veiga, A. (2013), "The Bologna process: inception, take-up and familiarity", Higher Education, Vol. 66, No. 1, pp. 59-77.

Nesheim, T. and Gressgard, L.G. (2014), "Knowledge sharing in a complex organization: antecedents and safety effects", Safety Science, Vol. 62, pp. 28-36.

Nissen, M.E. (2006), Harnessing knowledge dynamics: principled organizational knowing \& learning, IRM Press, Hershey.Nonaka, I. (1994), "A dynamic theory of organizational knowledge creation", Organization Science, Vol. 5, No. 1, pp. 14-37. 
Nonaka, I., and Takeuchi, H. (1995), The knowledge-creating company: how Japanese companies create the dynamics of innovation, Oxford University Press, Oxford.

Nonaka, I., Toyama, R. and Hirata, T. (2008), Managing flow: a process theory of the knowledge-based firm, Palgrave Macmillan, Houndmills.

Nonaka, I. and Zhu, Z. (2012), Pragmatic strategy: eastern wisdom, global success, Cambridge University Press, Cambridge.

O'Dell, C. and Hubert, C. (2011), The new edge in knowledge: how knowledge management is changing the way we do business, John Wiley \& Sons, New York.

Petty, R. and Guthrie, J. (2000), "Intellectual capital literature review: measurement, reporting and management", Journal of Intellectual Capital, Vol.1, No. 2, pp. 155-176.

Piber, M. and Pietsch, G. (2006), "Performance management in universities: the case of knowledge balance sheets analysed from a new institutionalist perspective", in Epstein, M.J. and Manzoni, J.F. (Eds.), Performance management and management control: improving organisations and society, Studies in Managerial and Financial Accounting, Vol. 16, pp. 379-401.

Polanyi, M. (1983), The tacit dimension, Peter Smith, Gloucester.

Powell, W.W. and Snellman, K. (2004), "The knowledge economy", Annual Review of Sociology, Vol. 30, pp. 199-220.

Ricceri, F. (2008), Intellectual capital and knowledge management: strategic management of knowledge resources, Routladge, London.

Romano, A., Passiante, G., Del Vechhio, P. and Secundo, G. (2014), "The innovation ecosystem as booster for the innovative entrepreneurship in the smart specialization strategy", International Journal of Knowledge-Based Development, Vol. 5, No. 3, pp. 271-288.

Roos, G., Pike, S. and Fernström, L. (2005), Managing intellectual capital in practice, Elsevier, Amsterdam.

Spender, J.C. (2014), Business strategy: managing uncertainty, opportunity, \& enterprise, Oxford University Press, Oxford.

Sánchez, M.P., Elena, S. and Castrillo, R. (2007), "The ICU report: an intellectual capital proposal for university strategic behavior". In Proceedings of the IMHE Conference, OECD.

Sánchez, M.P., Elena, S. and Castrillo, R. (2009), "Intellectual capital dynamics in universities: a reporting model", Journal of Intellectual Capital, Vol. 10, No. 2, pp. 307-324.

Secundo, G., De Beer, C., Schutte, C.S.L. and Passiante, G. (2017), "Mobilising intellectual capital to improve European universities' competitiveness: the technology transfer offices' role", Journal of Intellectual Capital, Vol. 18 No. 3, pp. 607-624.

Secundo, G., Del Vechio, P., Dumay, J. and Passiante, G. (2016), "Intellectual capital in the age of Big Data", IFKAD, University of Dresden, Germany, 15-17 June 2016, pp. 1903-1917.

Secundo, G., Elena Perez, S., Martinaitis, Z. and Leitner, K.H. (2017), “An intellectual capital framework to measure universities' third mission activities", Technological Forecasting \& Social Change (article in press). 
Secundo, G., Elena Perez, S., Martinaitis, Z. and Leitner, K.H. (2015), “An intellectual capital maturity model (ICMM) to improve strategic management in European universities: a dynamic approach", Journal of Intellectual Capital, Vol. 16, No. 2, pp. 419-442.

Secundo, G., Margherita, A., Elia, G. and Passiante, G. (2010), "Intangible assets in higher education and research: mission, performance or both?", Journal of Intellectual Capital, Vol. 11, No. 2, pp. 140-157.

Secundo, G., Elena Perez, S., Martinaidis, Z. and Leitner, K.H. (2014), "Intellectual capital management in European universities in times of changes: an IC maturity model", IFKAD, University of Basilicata, Italy, 11-13 June 2014, Matera, pp. 1095-1113.

Senge, P. (1999), The fifth discipline: the art \& practice of the learning organization, Random House.

Stacey, R.D. (2001), Complex responsive processes in organizations: learning and knowledge creation, Routledge, London.

Stewart, T. (1997), Intellectual capital: the new wealth of organizations, Nicholas Brealey Publishing, London.

Sveivy, K.E. (1997), The new organizational wealth: managing and measuring knowledge based assets, Berret-Koehler, San Francisco.

Sveiby, K.E. (2001), "A knowledge-based theory of the firm to guide in strategy formulation", Journal of Intellectual Capital, Vol. 2, No. 4, pp. 344-358.

Syrett, M. and Devine, M. (2012), "Managing uncertainty: strategies for surviving and thriving in turbulent times", Profile Books, London.

Teece, D.J. (2009), Dynamic capabilities \& strategic management: organizing for innovation and growth, Oxford University Press, Oxford.

Vătămănescu, E.M., Andrei, A.G., Dumitru, D.L. and Leovaridis, C. (2016), “Harnessing network-based intellectual capital in online academic networks. From the organizational policies and practices toward competitiveness", Journal of Knowledge Management, Vol. 20, No. 3, pp. 594-619.

Victor, D.H.F. (2007), "World universities ranking: generic and intangible features of world-class universities". In Sadlak, J. and Cai, L.N. (Eds.), The world-class university and ranking: aiming beyond status (pp. 55-60), UNESCO-CEPES, Bucharest, pp. 55-60.

Viedma, J.M. (2003), "In search of intellectual capital general theory", Electronic Journal of Knowledge Management, Vol. 1, No. 2, pp. 213-226.

Viedma, J.M. and Cabrita, M.R. (2012), Entrepreneurial excellence in the knowledge economy: intellectual capital benchmarking systems, Palgrave Macmillan, New York.

Wenger, E., Mcdermott, R., and Sntder, W.M. (2002), Cultivating communities of practice: a guide to managing knowledge, Harvard Business School Press, Boston.

Zack, M.H. (1999), “Developing a knowledge strategy”, California Management Review, Vol. 41, No. 3, pp. 125-145.

Zohar, D. and Marshall, I. (2000), SQ: Spiritual intelligence: the ultimate intelligence, Bloomsbury, London. 